https://doi.org/10.15407/ujpe66.3.231

Y. SIUSKO,${ }^{1}$ V. SVOBODA,${ }^{2}$ J. STOCKEL,${ }^{2}$ I. GARKUSHA, ${ }^{1,3}$ D. SOLYAKOV,${ }^{1,3}$

I. GIRKA,${ }^{3}$ V. VOLKOV ${ }^{3}$ D. BONDAR,${ }^{3}$ V. KONDRATENKO,${ }^{3}$ A. BOYCHENKO,${ }^{3}$

A. KRUPKA, ${ }^{3}$ D. BOLOTO ${ }^{3}$ D. DROZDOV ${ }^{3}$ O. SAlMIN,${ }^{3}$ A. SHCHIBRYA $^{3}$

${ }^{1}$ National Science Center Kharkov Institute of Physics and Technology

(1, Akademicheskaya Str., Kharkov 61108, Ukraine; e-mail: zhenya-syusko@kipt.kharkov.ua)

${ }^{2}$ Czech Technical University in Prague, Faculty of Nuclear Sciences and Physical Engineering

(Brehova 7, 11519 Praha 1)

${ }^{3}$ V.N. Karazin Kharkiv National University, School of Physics and Technology

(4, Svobody Sq., Kharkiv 61022, Ukraine)

\title{
BREAKDOWN PHASE \\ IN THE GOLEM TOKAMAK AND ITS IMPACT ON PLASMA PERFORMANCE
}

\begin{abstract}
The effect of the breakdown phase on subsequent plasma parameters in GOLEM tokamak is investigated remotely. The dependence of the breakdown voltage and the breakdown time on the time delay between the switchings-on of a toroidal magnetic field $B_{t}$ and a toroidal electric field $E_{t}$ for different groups of the pressure magnitudes is built. The performed experiments have shown that, for GOLEM tokamak, the shorter the temporal delay, the better are the mean plasma parameters. In addition, the breakdown phase is discussed in more details. In the discussion, the avalanche phase of the breakdown is analyzed. The dominant mechanism of particle losses during the avalanche phase, future steps, and tasks are discussed and set. The experiments on studying the breakdown phase have been carried out remotely on GOLEM tokamak by undergraduate students of V.N. Karazin Kharkiv National University.
\end{abstract}

Ke ywords: GOLEM tokamak, breakdown, avalanche, particle losses, plasma parameters.

\section{Introduction}

The initial stage (start-up) of a tokamak discharge can be divided into three phases: breakdown, plasma formation, and current rise. The breakdown phase is characterized by a low degree of ionization. Collisions between an electron and neutral molecules dominate. Plasma current is still low, and the rotational transform is negligible. After the breakdown, the next phase starts called the Coulomb phase, within which collisions between charged particles

(C) Y. SIUSKO, V. SVOBODA, J. STOCKEL,

I. GARKUSHA, D. SOLYAKOV, I. GIRKA,

V. VOLKOV, D. BONDAR, V. KONDRATENKO,

A. BOYCHENKO, A. KRUPKA, D. BOLOTO,

D. DROZDOV, O. SALMIN, A. SHCHIBRYA, 2021

SSN 2071-0194. Ukr. J. Phys, 2021. Vol. 66, No. 3 dominate. Plasma current is sufficiently high, magnetic surfaces arise, and the confinement is expected to increase significantly. The start-up phase of a discharge in a TM-I-MH tokamak was investigated in [1]. The mechanism of particle losses in the phase preceding the formation of a rotational transform was studied in the TM-I-MH tokamak in [2], and the importance of stray magnetic fields was discussed. The breakdown phase directly affected the ultimate properties of the plasma: the production of runaway electrons, impurities, equilibrium, stability, etc. The breakdown phenomenon was studied experimentally in the SINP tokamak [3] for different magnitudes of the filling pressure, toroidal electric field, toroidal magnetic field, and vertical magnetic field by using a hot filament preionization system. In 
addition, the breakdown was studied in the PRETEXT Tokamak [4]. There were investigated the effects of the limiter bias, working gas, and pressure on the breakdown. In [5], the tokamak breakdown phase driven by a pure Ohmic heating with implicit particles were simulated by the particle in cell/Monte Carlo collision (PIC/MCC) method. It was shown that the avalanche process can be separated into two stages. One was the fast avalanche stage, in which the plasma was heated by the induced toroidal electric field. The other was the slow avalanche stage, which began after the plasma particle density had reached $10^{15} \mathrm{~m}^{-3}$. In this paper, the influence of the working gas pressure and the toroidal magnetic field on the breakdown phase and subsequent plasma parameters is investigated. The Ukrainian group of undergraduates from the School of Physics and Technology at V.N. Karazin Kharkiv National University had carried out the experiments on studying the breakdown phase remotely due to the remote control capability on GOLEM tokamak [6, 7] on March, 2019. It had helped the students to master the skills of planning and carrying out modern experiments with modern equipment, as well as to establish cooperation and strengthen scientific ties.

\section{Experimental Set-Up and Diagnostics}

The GOLEM tokamak (formerly CASTOR) at the Czech Technical University is demonstrated to be an educational and research device for domestic and foreign students. This tokamak was brought to the IPP Prague in 1977 from Kurchatov Institute of Atomic Energy in Moscow, Russia. The name TM-1-

Table 1. Main parameters of tokamak GOLEM

\begin{tabular}{|l|c|}
\hline \multicolumn{1}{|c|}{ Parameter } & Value \\
\hline Vessel major radius & $R_{0}=0.4 \mathrm{~m}$ \\
Vessel minor radius & $r_{0}=0.1 \mathrm{~m}$ \\
Radius of poloidal limiter & $a_{\mathrm{lim}}=0.085 \mathrm{~m}$ \\
Toroidal magnetic field & $B_{\mathrm{t}}<0.5 \mathrm{~T}$ \\
Plasma current & $\mathrm{I}_{p}<8 \mathrm{kA}$ \\
Central electron density & $n_{e} \approx(0.2-3) \times 10^{19} \mathrm{~m}^{-3}$ \\
Effective ion charge & $Z_{\mathrm{eff}} \approx 2.5$ \\
Electron temperature & $T_{e}<100 \mathrm{eV}$ \\
Discharge duration & $\tau_{p}<25 \mathrm{~ms}$ \\
Energy confinement time & $\tau_{e}<50 \mu \mathrm{s}$ \\
\hline
\end{tabular}

MH was substituted by the acronym CASTOR: Czech Academy of Science TORus after reconstruction in 1985. After the shut down in 2006, CASTOR was transported to the Faculty of Nuclear Sciences and Physical Engineering of the Czech Technical University in Prague and reinstalled [8]. Now, it operates under a new name GOLEM as a device for the education and research work. The main parameters of tokamak GOLEM are shown in Table 1. The more detailed description of the tokamak is given in [9]. Diagnostics, which are used for the experiment, are listed in the Table 2 .

\subsection{Remote handling of GOLEM tokamak}

For the remote handling, one needs a computer with the connection with the Internet and the agreement of the chief operator of GOLEM. After reviewing and accepting the experiment plan, the remote operators take access to the site with the remote control room of GOLEM. There, they can choose parameters which they need according to the plan for the experiments. Parameters that can be pre-selected by remote users are shown in Table 3 . When the initial parameters of the pulse are accepted, then a discharge can be executed. The main experimental results and the data from all the diagnostics are loaded in a couple of minutes into the database, which is also available via the Internet for everyone in this site [10]. When somebody wants to process data, he/she can find the corresponding shot in the database. There are utilities for a faster data processing in the site [11]. These utilities help one to find the necessary pulse numbers, withdraw the specified diagnostic data or some calculated values in the text or graphical form. This is very comfortable and helpful, when one needs to process a big massive of data in the GOLEM database.

\subsection{Preparation to the breakdown phase}

The tokamak is pumped down to the pressure $10^{-4} \div$ $10^{-3} \mathrm{~Pa}$. The tokamak vessel is heated to $\sim 180{ }^{\circ} \mathrm{C}$ for $60 \mathrm{~min}$, and the cleaning glow discharge in $\mathrm{He}$ is applied for $30 \mathrm{~min}$ to remove impurity molecules from the inner wall of the vessel. The working gas is hydrogen. The plasma density $\sim 10^{17} \div 10^{18} \mathrm{~m}^{-3}$ is required at the breakdown phase. The density of neutral atomic hydrogen should be a comparable one. Therefore, the initial pressure of $\mathrm{H}_{2}$ should be in the interval $\sim 0.002 \div 0.02 \mathrm{~Pa}$. The breakdown of 
Table 2. Diagnostics, which are used for the experiment

- A wire loop laid toroidally along the vacuum vessel measuring the loop voltage $U_{\text {loop }}$.

- A small coil located on the vessel measuring the voltage proportional to the time derivative of the toroidal magnetic field

- A Rogowski coil surrounding the vessel (and the plasma) ring poloidally measuring the voltage proportional to the time derivative of the total vessel and plasma current $I_{v+p}$.

- A microwave interferometer system (not shown) measuring the line averaged density $n_{e}$

the working gas in tokamaks starts after inducing a toroidal magnetic field (by driving current in the toroidal field coils) and the toroidal electric field coils (by driving current in the primary winding of the tokamak transformer). However, at least a single charged particle (electron) has to be present in the tokamak vessel, which is filled by the working gas at the sufficient pressure. In addition, in our case, the pre-ionization is made with using a tungsten filament, which generates some free electrons. These electrons are accelerated by the toroidal electric field $E_{t}=U_{\text {loop }} / 2 \pi R_{0}$ (where $U_{\text {loop }}$ is the loop voltage, $R_{0}$ is the major radius) and follow the circular magnetic field line. When the energy of electrons is sufficiently high $\left(>13.6 \mathrm{eV}\right.$ in $\left.\mathrm{H}_{2}\right)$, they ionize molecules of the working gas and produce pairs of ions and electrons. A secondary electron is again accelerated and ionizes a molecule of $\mathrm{H}_{2}$. This process further developes as an avalanche, which leads to the breakdown of the gas, and, after a short time (of the order of milliseconds), the tokamak vessel is filled by a "fully" ionized plasma.

\section{Experimental Results}

\subsection{Discharge parameters preselected via the Internet to investigate the breakdown phase}

In our experiments, $\mathrm{H}_{2}$ is selected as the working gas, and the electron gun is used for its periodization. The charging voltage of the condenser bank for the toroidal magnetic field is $U_{\mathrm{BT}}=1300 \mathrm{~V}$ and is kept unchanged for the whole experimental series. The charging voltage of the condenser bank for the primary winding of the transformer $U_{\mathrm{CD}}=500 \mathrm{~V}$ is also kept unchanged for the whole experimental series. First, the pressure of the working gas is preselected by a gate valve to be of $6 \mathrm{mPa}$, and the time delay $T_{\mathrm{CD}}$ between the triggers of $U_{\mathrm{BT}}$ and $U_{\mathrm{CD}}$ is changed from 0 to $5000 \mu \mathrm{s}$ by steps of $500 \mu \mathrm{s}$, i.e., through 11 shots. The same scan is performed
Table 3. The parameters of GOLEM

tokamak which can be selected via the Internet

\begin{tabular}{|l|c|c|}
\hline $\begin{array}{c}\text { Basic parameters which can } \\
\text { be preselected remotely }\end{array}$ & $\begin{array}{c}\text { Maximum } \\
\text { value }\end{array}$ & Recommended \\
\hline $\begin{array}{l}\text { The magnitude of capacitors } \\
\text { charge voltage for powering } \\
\text { toroidal coils } U_{\mathrm{BD}}\end{array}$ & 1300 \\
$\begin{array}{l}\text { The magnitude of capacitors } \\
\text { charge voltage for powering } \\
\text { the primary winding } \\
\text { of the transformer } U_{\mathrm{CD}}\end{array}$ & $800 \leq U_{\mathrm{BD}} \leq 1000 \mathrm{~V}$ \\
$\begin{array}{l}\text { Time delay } T_{\mathrm{CD}} \\
\text { The pressure of working } \\
\text { gas } p\end{array}$ & $20 \mathrm{~ms}$ & $0 \leq T_{\mathrm{CD}} \leq 10 \mathrm{~ms}$ \\
$\begin{array}{l}\text { Periodization } \\
\text { Working gas }\end{array}$ & $\begin{array}{c}50 \mathrm{mPa} \\
\text { On or off } \\
\mathrm{H}_{2} \text { or He }\end{array}$ & $\begin{array}{c}\text { Can be chosen } \\
\text { Con }\end{array}$ \\
\hline
\end{tabular}

for higher pre-selected pressures - 8, 10, 12, and $14 \mathrm{mPa}$. Therefore, 55 shots are carried out in a total in this experiment, from No. 29859 to No. 29913.

\subsection{Results}

The temporal evolution of a typical ("good") discharge in hydrogen, for example, No.29871, is shown in Fig. 1. Pre-defined discharge parameters are as follows: pressure of the working gas is requested to be $8 \mathrm{mPa}$ and $7.88 \mathrm{mPa} ; U_{\mathrm{BT}}=1300 \mathrm{~V} ; U_{\mathrm{CD}}=500 \mathrm{~V}$; and time delay is $0.5 \mathrm{~ms}$.

We see that the plasma life time (or discharge duration) is $16.6 \mathrm{~ms}$ (from $7.6 \mathrm{~ms}$ to $24.2 \mathrm{~ms}$ ), the maximum plasma current is $\sim 6 \mathrm{kA}$, the maximum central electron temperature is up to $80 \mathrm{eV}$, the edge safety factor $q(a)$ is slightly above 3 , and the maximum line average density reaches $8 \times 10^{18} \mathrm{~m}^{-3}$. However, the first stage of the discharge should be examined more precisely. The breakdown time $\left(\tau_{\mathrm{br}}\right)$ and the breakdown voltage $\left(U_{\mathrm{BD}}\right)$ are defined from the plot of the main plasma parameteres during the discharge. The 


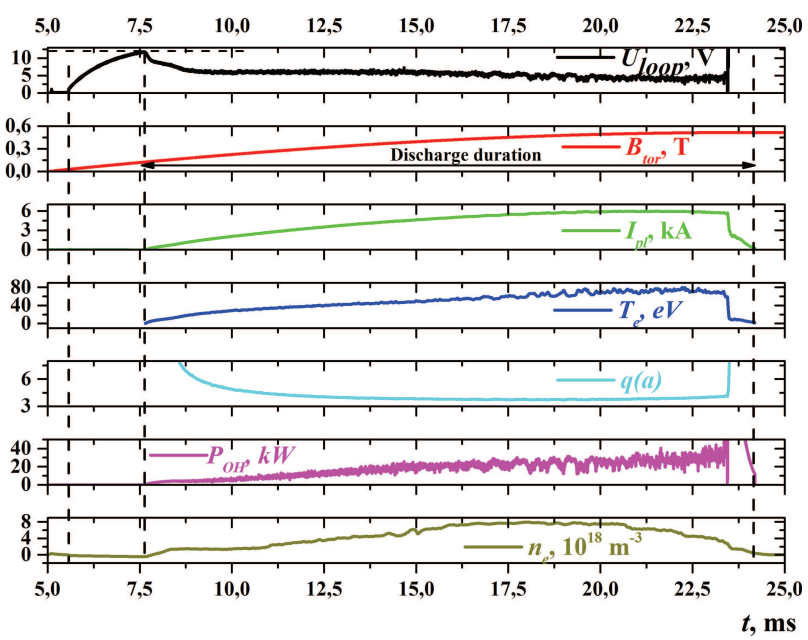

Fig. 1. Plot of the temporal evolution of a good shot No. 29871 containing selected traces available from the GOLEM database, where from the top to the bottom: $U_{\text {loop }}$ is the loop voltage; $B_{\mathrm{t}}$ is the toroidal magnetic field; $I_{\mathrm{pl}}$ is the plasma current; $T_{e 0}$ is the central electron temperature; $q(a)$ is the safety factor; $P_{\mathrm{OH}}$ is the Ohmic heating power; $n_{e}$ is the line electron density

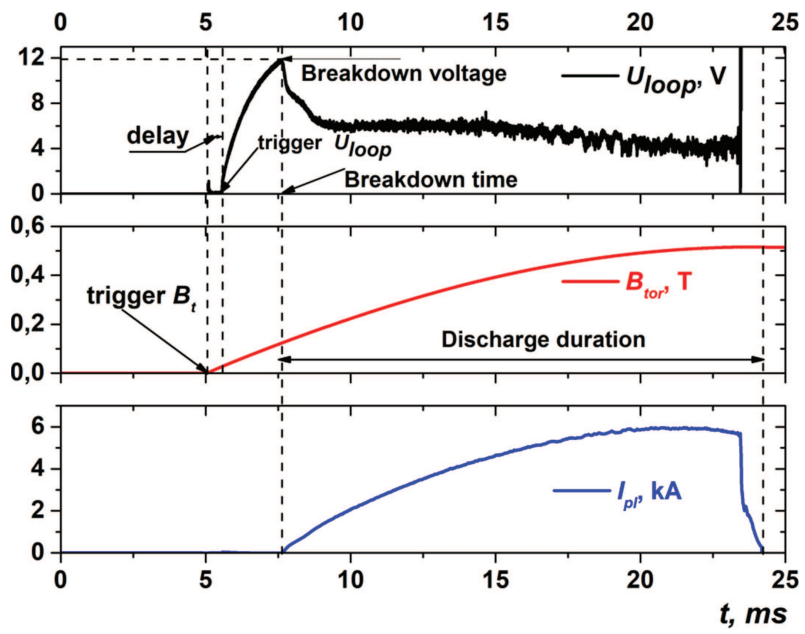

Fig. 2. Plot of the main plasma parameteres. (Shot No. 29871). Here, from the top to the bottom: $U_{\text {loop }}$ is the loop voltage; $B_{\text {tor }}$ is toroidal magnetic field, $I_{\mathrm{pl}}$ is plasma current

closer look at the breakdown phase of the discharge (No. 29871) is shown in Fig. 2.

The plasma breakdown is manifested by an abrupt drop of the loop voltage and a sharp increase of the plasma current at $t=7.6 \mathrm{~ms}$. The breakdown time $\left(\tau_{\mathrm{br}}\right)$ is defined as the time lag between the start of the loop voltage signal (the switching-on of

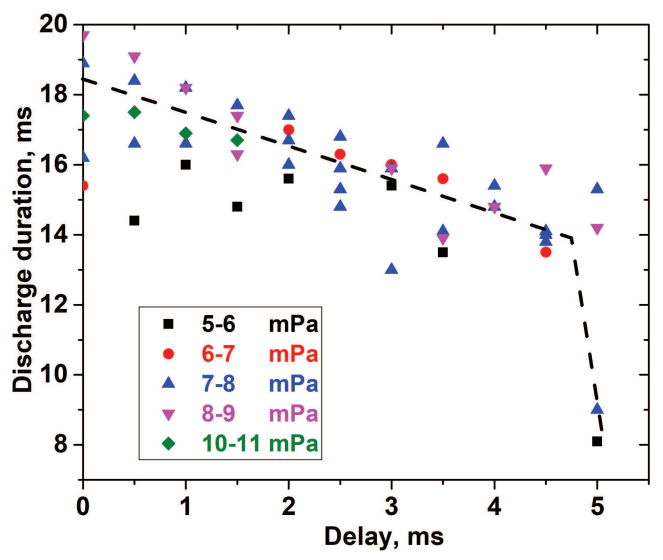

Fig. 3. Discharge duration versus the time delay for several groups of the pressure of the working gas

$\left.U_{\mathrm{CD}}\right)$ and the breakdown of the working gas. At the breakdown, the plasma resistivity $R_{\text {plasma }}=\frac{U_{\text {loop }}}{I_{\text {plasma }}}$ drops below the resistivity of the GOLEM vacuum vessel, which is $\sim 10 \mathrm{~m} \Omega$. We see that the delay between the switching-on of $B_{\mathrm{t}}$ and the switching-on of $U_{\mathrm{CD}}$ defines the value of the toroidal magnetic field at which the loop voltage (or the toroidal electric field $\left.E_{\mathrm{t}}\right)$ is applied. So, increasing this delay, the toroidal magnetic field at the start-up increases as well. Let us analyze the influence of the time delay on the plasma parameters of the breakdown phase of the discharge for different values of the working gas pressure. It has to be noted that, in GOLEM, one cannot set precisely the same given pre-selected value to the filling gas pressure. Therefore, for a more convenient presentation, the discharges are divided into several groups according to the pressure: $5 \div 6 \mathrm{mPa}$, $6 \div 7 \mathrm{mPa}, 7 \div 8 \mathrm{mPa}, 8 \div 9 \mathrm{mPa}$ and $10 \div 11 \mathrm{mPa}$. Figure 3 presents the dependence of the discharge duration versus the time delay for selected groups of the pressure of the working gas.

A reduction of the discharge duration with increasing the time delay is evident. It is also seen that the optimum pressure is in the interval $7 \div 11 \mathrm{mPa}$. Note also a rather dramatic reduction of the discharge duration for lower pressures at the time delay $\sim 5 \mathrm{~ms}$. Figure 4 shows the dependences of the breakdown voltage and the breakdown time on the time delay.

One can clearly see that the breakdown voltage, as well as the breakdown time, increases with the time delay. When the time delay is more than two milliseconds, the breakdown voltage has a much wider

ISSN 2071-0194. Ukr. J. Phys. 2021. Vol. 66, No. 3 

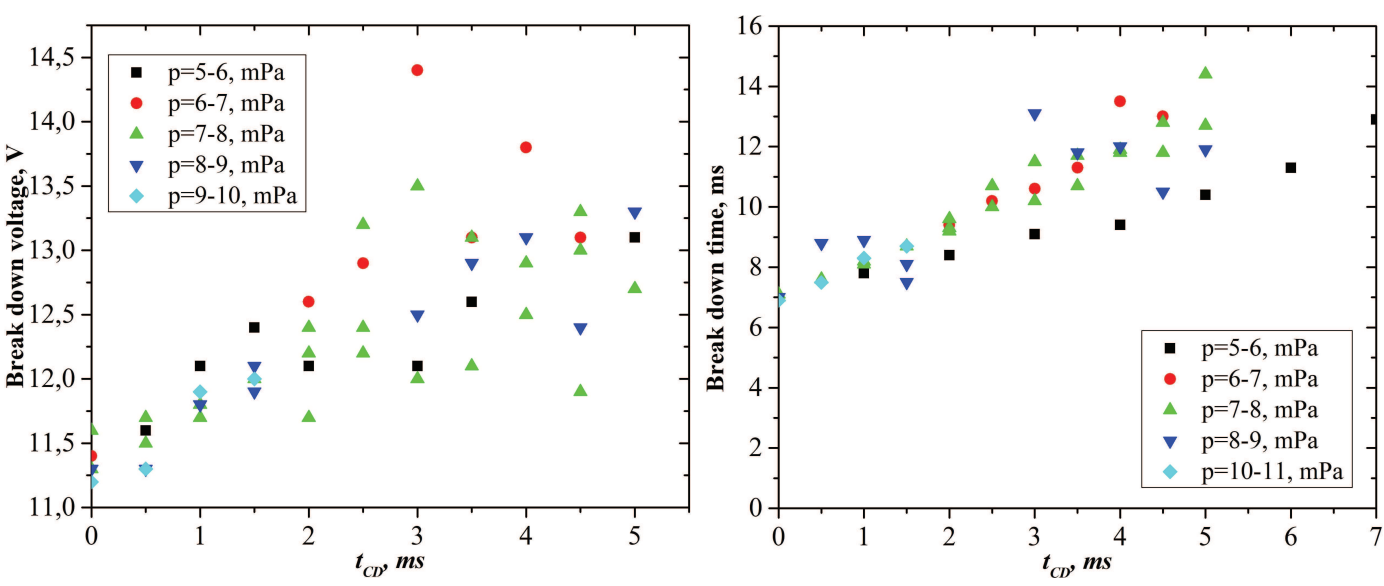

Fig. 4. The dependencies of the breakdown voltage (left panel) and the breakdown time (right panel) on the time delay

spread and has unpredictable values. The right panel of Fig. 4 shows that the breakdown time also increases with the time delay. An increase of the gas pressure also leads to a later breakdown time. In the GOLEM database, mean values of various plasma parameters are automatically calculated according to a software presented in the wiki pages of GOLEM tokamak the [11]. Figure 5 shows the dependences of some of them on the time delay.

It is seen that all important mean plasma parameters reduce with increasing the time delay. However, it has to be noted that mean values also reflect the duration of the discharge in some way. As it is claimed before, the time delay is proportional to the toroidal magnetic field during the breakdown phase of the discharge. Therefore, we analyze this phase in more details to have a better insight into the underlying physics.

\section{Discussion}

\subsection{Analysis of the avalanche phase of a discharge}

The process in a tokamak, which leads to the breakdown, is called the avalanche phase (Townsend avalanche). The avalanche phase is defined as the time interval between the application of the loop voltage and the breakdown of the working gas. The evolutions of several macroscopic parameters of discharge No. 29871 during the avalanche phase are plotted in Fig. 6. We clearly observe the visible emission, which is the sign of the excitation/ionization of the working

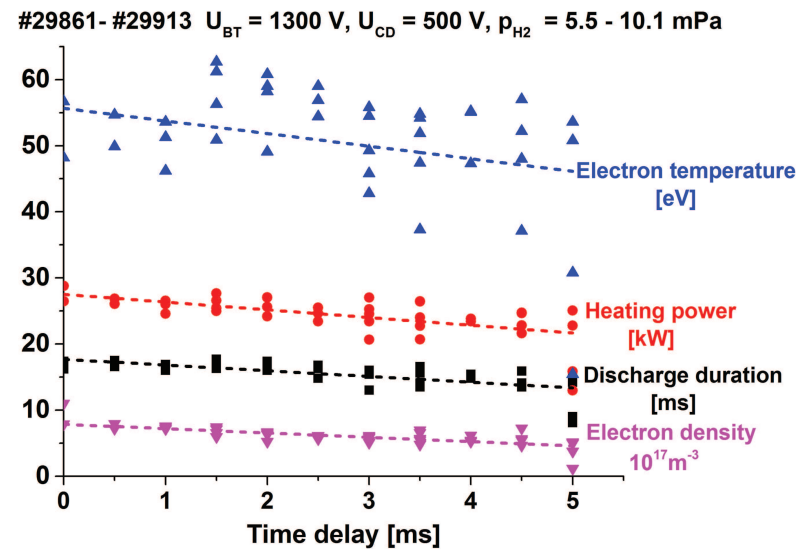

Fig. 5. Variation of mean plasma parameters with the time delay for all intervals of the working gas pressure

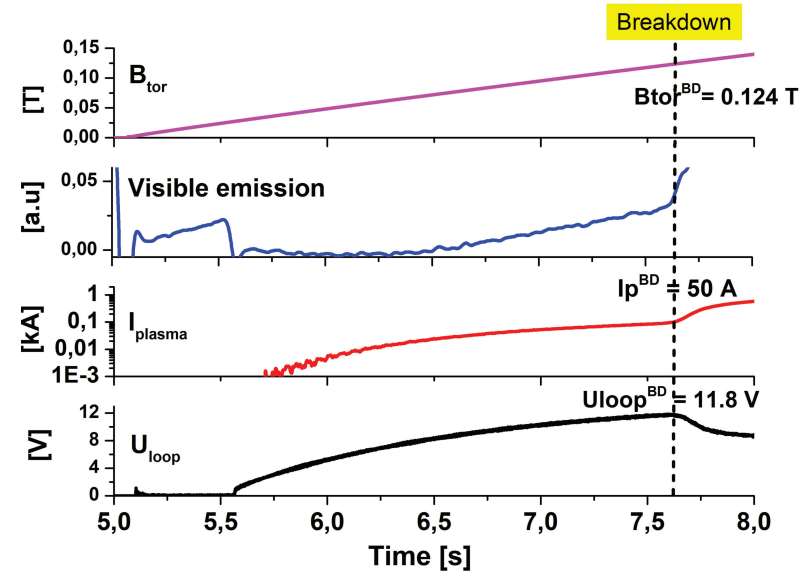

Fig. 6. Temporal evolutions of selected plasma parameters during the avalanche phase of discharge No. 29871 


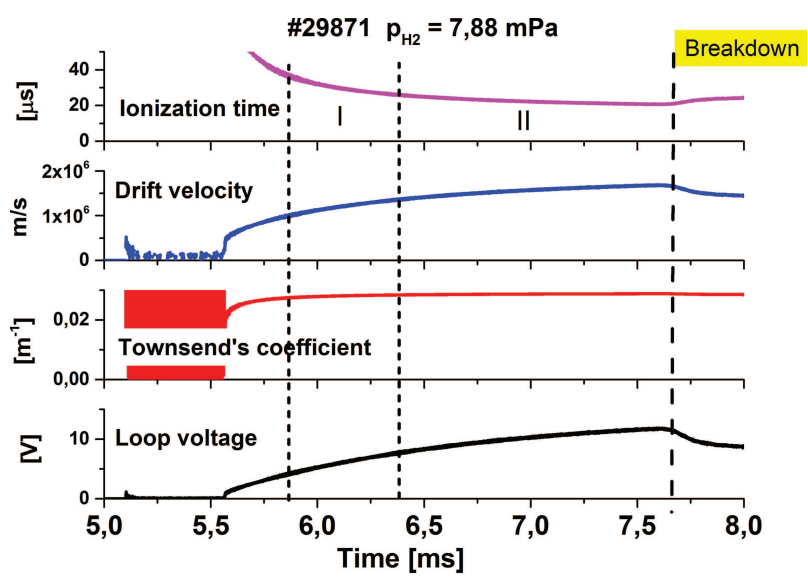

Fig. 7. Temporal evolution of selected quantities during the avalanche phase of discharge No. 29871 derived according to expressions (1)-(3) and the oop voltage

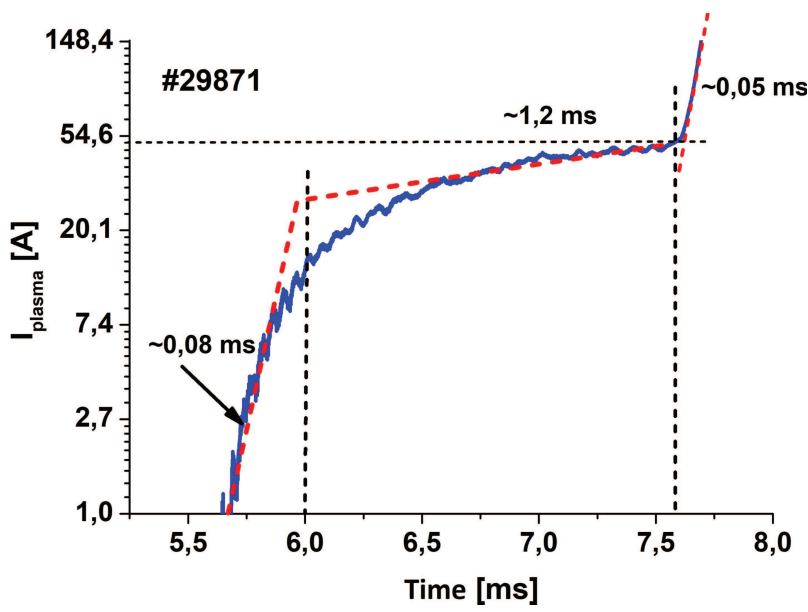

Fig. 8. Evolution of the plasma current during the avalanche phase of discharge No. 29871

gas by the avalanche of preionization electrons. These electrons are accelerated to the drift velocity by the toroidal electric field:

$v_{\mathrm{D}}=6.910^{4} \sqrt{\frac{E_{T}}{p_{\mathrm{H}_{2}}}},[\mathrm{~m} / \mathrm{s}, \mathrm{V} / \mathrm{m}, \mathrm{Pa}]$,

where $E_{T}=\frac{U_{\text {loop }}}{2 \pi R_{0}}$ is the induced toroidal electric field, and $R_{0}=0.4 \mathrm{~m}$ is the major radius of GOLEM tokamak. The number of ionizations per unit length is given by the first Townsend coefficient $\alpha$ :

$\alpha=A p_{\mathrm{H}_{2}} \exp \left\{\frac{B p_{\mathrm{H}_{2}}}{E}\right\}, \mathrm{m}^{-1}$, where $A=3.75$ and $B=99$ for molecular hydrogen [12]. The characteristic ionization time $\tau_{\text {ion }}$ is defined as:

$\tau_{\text {ion }}=\frac{1}{\alpha v_{\mathrm{D}}},\left[\mathrm{s}, \mathrm{m}^{-1}, \mathrm{~m} / \mathrm{s}\right]$

An example of temporal evolutions of the abovementioned quantities is plotted in Fig. 7 for discharge No. 29871. Figure 8 shows the more detail evolution of the plasma current during the avalanche phase. It is proportional to the plasma density, because collisions between avalanche electrons and neutrals (hydrogen atoms/molecules) dominate:

$I_{p} \sim n_{e} v_{\mathrm{D}}$

One can see that the rise time of the plasma current at the very beginning of the avalanche is comparable with the ionization time which is in the interval $\tau_{\text {ion }} \sim 30-40 \mu$ s. However, one can see in the same figure that the rise time of the plasma current is significantly slowed, being characterized by the time constant $\tau_{a}>1 \mathrm{~ms}$, which is by the order of magnitude higher than the ionization time. The losses of charged particles from the plasma column are evident reasons for this difference:

$n_{e}(t)=n_{e o} \exp \left[\frac{t}{\tau_{\text {ion }}}-\frac{t}{\tau_{\text {loss }}}\right]$.

These particle losses can be characterized by a time $\tau_{\text {loss }}$. The relation between the all those time constants is [13]:

$\frac{1}{\tau_{a}}=\frac{1}{\tau_{\text {ion }}}-\frac{1}{\tau_{\text {loss }}}$

One can estimate the characteristic loss time using the experimentally measured $\tau_{a} \sim 10 \tau_{\text {ion }}$ as follows:

$\tau_{\text {loss }}=\tau_{\text {ion }} \frac{1}{1-\frac{\tau_{\text {ion }}}{\tau_{a}}}=\frac{10}{9} \tau_{\text {ion }}$.

One can clearly see that the loss time has to be comparable (but slightly higher) with the ionization time to match the experiment. The mechanism for sufficiently fast particle losses during the avalanche was proposed in the pioneering paper by Martin Valovic [14]. The plasma polarization due to a perpendicular stray magnetic field $B_{\text {perp }}$ was experimentaly demonstrated to be responsible for fast particle losses during 
the avalanche phase. This mechanism is depicted by a schematic drawing shown in Fig. 9 assuming that the stray magnetic field has only the vertical component $B_{\text {perp }}=B_{z}$. Perpendicular stray magnetic fields, which are always present in the tokamak vessel, cause the drift of charged particles in the perpendicular direction with respect to the toroidal magnetic field. The avalanche electrons propagate along the helical magnetic field line with a drift velocity, while the ion velocity is much smaller. This causes the separation of the electron and ion components and, consequently, results in the formation of the perpendicular electric field $E_{\text {perp }}$. The expression for the perpendicular electric field was derived (and proved by the experiment) in [15] as:

$E_{\text {perp }} \approx \frac{E_{\text {tor }} B_{\text {tor }}}{B_{\text {perp }}}$.

The corresponding cross field velocity characterizing the plasma losses is $\nu_{\text {loss }} \approx \frac{E_{\text {perp }}}{B_{\text {tor }}}$, and the resulting loss time is:

$\tau_{\mathrm{loss}} \approx \frac{a_{\mathrm{lim}}}{\nu_{\mathrm{loss}}} \approx \frac{a_{\mathrm{lim}} B_{\mathrm{perp}}}{E_{\mathrm{tor}}}$

where $a_{\lim }$ is the radius of the poloidal limiter of GOLEM. As the next step, one has to estimate the perpendicular stray magnetic field $B_{\text {perp }}$ in GOLEM. There are three main sources of the perpendicular stray magnetic fields in GOLEM during the avalanche phase:

- The stray vertical magnetic field generated by the current induced in the conducting vessel of GOLEM, $I_{\text {vessel }}=\frac{U_{\text {loop }}}{R_{\text {vessel }}}$, where $R_{\text {vessel }}=0.001 \Omega$.

- The stray magnetic field generated by the presence of the iron core transformer.

- The stray magnetic field generated by the imperfect alignment of toroidal field coils and cables of their power supply.

The stray vertical magnetic field due to the current induced in the toroidal tokamak vessel is proportional to the vessel current estimated as [16]: $B_{z}=(0.4 \div 0.5) \times 10^{-5}[\mathrm{~T}, \mathrm{~V}]$. According to Eqs. (8) and (9), the resulting loss time is (within some expected error bars $) \tau_{\text {loss }}^{\text {vessel }} \approx \frac{\alpha B_{z}}{E_{\text {tor }}}=(0.04 \div 0.05) \times$ $10^{-4} \frac{2 \pi R_{0} a U_{\text {loop }}}{U_{\text {loop }}}=(1 \div 1.2) \times 10^{-5}[\mathrm{~s}]$. It is comparable with the ionization time $\tau_{\text {ion }}$. It is important to emphasize that this loss time depends only on the geometry of GOLEM tokamak, being independent

ISSN 2071-0194. Ukr. J. Phys. 2021. Vol. 66, No. 3

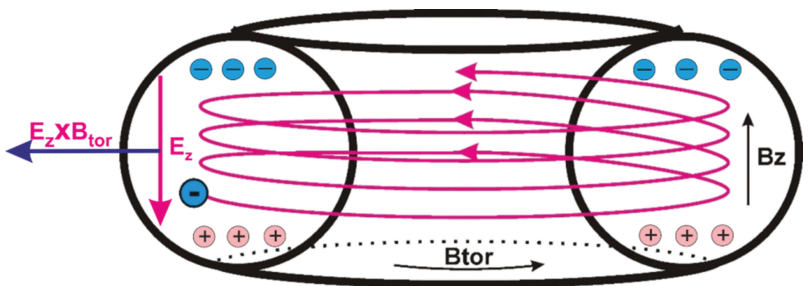

Fig. 9. Formation of the perpendicular electric field $E_{z}$ and consequent losses due to the cross-field drift motion $E_{z} \times B_{\text {tor }}$

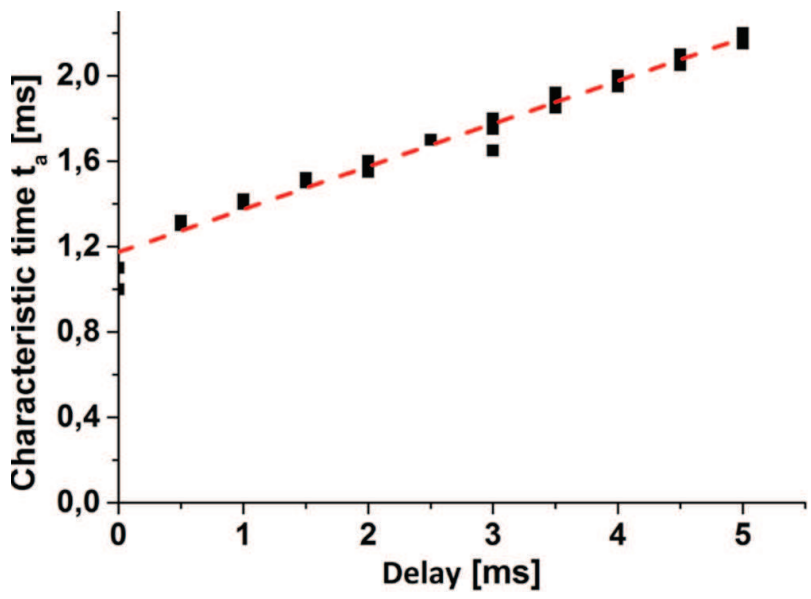

Fig. 10. Dependence of the characteristic (avalanche) time $\tau_{a}$ on the time delay

of pre-selected discharge parameters. Therefore, one can suggest this loss time as the basic one. It is evident that the vessel stray magnetic field is superimposed by the stray field of the iron core transformer of GOLEM. Unfortunately, we don't know how to estimate this quantity. But, definitely, the resulting loss time has to be higher. Now, the stray field due to the toroidal field winding is to be discussed. The dependence of the avalanche time on the time delay is plotted in Fig. 10. One clearly observes the linear dependence of the avalanche time on the time delay, i.e., on the value of the toroidal magnetic field during the avalanche phase. This demonstrates that the stray magnetic field of TF coils is significant one. However, these stray fields, which should be well below $1 \%$ of $B_{\text {tor }}$, can be hardly measured experimentally against a high background.

\section{Conclusions}

The Ukrainian group of undergraduate students from the School of Physics and Technology, V.N. Karazin 
Kharkiv National University, have carried out remotely the experiments to study the breakdown phase. This has become possible due to the remote control capability on GOLEM tokamak. The investigated breakdown phase depends on the filling pressure of the working gas $\mathrm{H}_{2}$ and the time delay between the start of the toroidal magnetic field and the trigger of the current in the primary winding of the GOLEM transformer. The experimentally measured dependences of macroscopic discharge parameters allow one to conclude the following.

- Increasing the time delay leads to a reduction of the discharge duration. A rather dramatic reduction of the discharge duration for the lowest pressures at the time delay $\sim 5 \mathrm{~ms}$ is also observed.

- Increasing the time delay is followed by an increase of the breakdown voltage and the breakdown time. This may cause an enhanced generation of supra-thermal (runaway) electrons, which is always an undesirable phenomenon in tokamaks.

In summary, the best plasma performance on GOLEM tokamak is achieved at the lowest time delays (from 0 to $1 \mathrm{~ms}$ ) and the filling pressures of the working gas $\left(\mathrm{H}_{2}\right)$ in the interval $7 \div 9 \mathrm{mPa}$. The avalanche phase of the breakdown is also analyzed. Several characteristic quantities are calculated under the GOLEM conditions: the drift velocity of electrons in molecular hydrogen, the number of ionizations per unit length (Townsend coefficient $\alpha$ ) and the characteristic ionization time $\tau_{\text {ion }}$. The characteristic (avalanche) time $\tau_{\alpha}$ is observed to increase linearly with the time delay. The plasma polarization caused by the stray magnetic fields which occur during the avalanche phase is concluded to be the dominant mechanism of particle losses.

The Ukrainian team sincerely thanks the Czech Technical University in Prague, Faculty of Nuclear Sciences and Physical Engineering, for the opportunity to perform the remote control and exploitation of GOLEM tokamak. This work has been supported by IAEA CRP F13019 "Network of Small and Medium Size Magnetic Confinement Fusion Devices for Fusion Research" and the European Fusion Education Network (FuseNet). This work has been carried out within the framework of the EUROfusion Consortium and has received a funding from the Euratom research and training programme 2014-2018 and 2019-2020 under grant agreement
No. 633053. The views and opinions expressed herein do not necessarily reflect those of the European Commission. The work has been performed under EUROfusion WP EDU.

1. A. Raicu et al. The thermal ionization phase during the plasma formation in TM-1-MH tokamak. Czechoslovak $J$. Phys. 37 (7), 850 (1987).

2. H. Prinzler, P. Heymann, J. Stockel et al. Investigations of the start up phase in the TM-1-MH tokamak. Czechoslovak J. Phys. 34, 665 (1987).

3. P.K. Chattopadhyay, R. Pal, N.R. Ray, P.K. Gupta. Breakdown and preionization experiments in the SINP tokamak. Nuclear Fusion 36 (9), 1205 (1996).

4. J.F. Benesch. Breakdown in the PRETEXT Tokamak (Ph.D. Thesis Texas Univ., Austin. Dept. of Physics, 1981).

5. W. Jiang, Y. Peng, Y. Zhang, G. Lapenta. Numerical modeling of tokamak breakdown phase driven by pure Ohmic heating under ideal conditions. Nucl. Fus. 56 (12), 126017 (2016).

6. V. Svoboda et al. Remote operation of the GOLEM tokamak with hydrogen and helium plasmas. J. Phys.: Conf. Ser. 768, 1 (2016).

7. V. Svoboda et al. Multi-mode remote participation on the GOLEM tokamak. Fusion Engineering and Design 86, 1310 (2011)

8. J. Brotankova. Breakdown in the PRETEXT Tokamak (Ph.D. Thesis Institute of Plasma Physics., Prague. Dept. of Surface and Plasma Science, 2009).

9. T. Markovic. Measurement of Magnetic Fields on GOLEM Tokamak (Diploma. Czech Technical University in Prague., Prague. Dept. of Physics, 2012).

10. http://golem.fjfi.cvut.cz/shots/0/

11. http://golem.fjfi.cvut.cz/utils/

12. R. Papoular. The genesis of toroidal discharges. Nucl. Fus. 16, 37 (1976).

13. B. Lloyd, G.L. Jackson, T.S. Taylor, E.A. Lazarus, T.C. Luce, R Prater. Low voltage Ohmic and electron cyclotron heating assisted startup in DIII-D. Nucl. Fus. 31, 2031 (1991).

14. M. Valovic. Convective losses during current initiation in tokamaks. Nucl. Fus. 27, 599 (1987).

15. B. Lloyd, P.G. Carolan, C.D. Warrick. ECRH-assisted start-up in ITER. Plasma Physics and Controlled Fusion 38, 1627 (1996).

16. T. Markovic. 3D simulation of the stray magnetic field on GOLEM (private communication).

Received 26.06.20

ISSN 2071-0194. Ukr. J. Phys. 2021. Vol. 66, No. 3 
Є. Сюсъко, Я. Штокель, В. Свобода,

І. Гаркуша, Д. Соляков, І. Гірка, В. Волков, Д. Бондар,

В. Кондратенко, А. Бойченко, А. Крупка, Д. Болото,

Д. Дроздов, О. Салмін, А. Щибря

\section{ФАЗА ПРОБОЮ НА ТОКАМАЦІ}

GOLEM ТА ÏÏ ВПЛИВ НА ПАРАМЕТРИ ПЛАЗМИ

На токамаці GOLEM було досліджено вплив фази пробою на подальші (післяпробійні) параметри плазми. Для різних підгруп тиску побудовано залежність напруги та часу настання пробою від періоду затримки між моментом вмикання тороїдального магнітного поля $B_{t}$ та моментом вмикання тороїдального електричного поля $E_{t}$. Проведені експе- рименти на токамаці GOLEM показали, що чим коротша часова затримка між полями - тим кращі середні параметри плазми. Крім того, фазу пробою обговорено більш детально. В ході обговорення проаналізовано лавинну фазу пробою. Встановлено домінуючий механізм втрати частинок під час лавинної фази, обговорені майбутні кроки досліджень, поставлені нові завдання. Експерименти з вивчення фази пробою були проведені дистанційно на токамаку GOLEM студентами магістратури Харківського національного університету ім. В.Н. Каразіна.

Ключові слова: GOLEM токамак, пробій, лавина, втрати частинок, параметри плазми. 